\title{
Espacialização da evapotranspiração na bacia hidrográfica do rio Ipojuca - PE, Brasil
}

\author{
Wagner Rodolfo de Araújo ${ }^{a^{*}}{ }^{\infty}$, Raimundo Mainar de Medeiros ${ }^{b}{ }^{\bullet}$, Manoel Vieira de França $a^{b}$ \\ a Universidade Estácio de Sá, Brasil \\ ${ }^{\mathrm{b}}$ Universidade Federal Rural de Pernambuco, Brasil \\ *Autor correspondente (wagneraraujops@gmail.com)
}

\section{N F O}

\section{Keywords}

water balance variability

human impact

agricultural planning

\section{Palavras-chaves}

balanço hídrico variabilidade

impacto humano planejamento agrícola

\begin{abstract}
A B S T R A C T
Spatialization of evapotranspiration in the Ipojuca river hydrographic basin - PE, Brazil

Evapotranspiration is one of the main components of the water balance, being useful in the quantification of regional water availability. The objective is to characterize the climatic conditions of evapotranspiration in the hydrographic basin of the Ipojuca River and perform its interpolation, elaborating maps representative of the monthly and annual distribution in addition to the variability of high and low evapotranspiration by the kriging method. It used series of monthly and annual precipitation data and average air temperature in the period 1962 - 2018. The temperature method was through the Estima_T software. They carried out the climatic classification according to Köppen and Thornthwaite. The estimated municipal data showed good accuracy of evaporative values and its consistency is $95 \%$ reliable. Deforestation, burning and silting up of rivers, lakes, ponds, streams, streams and water tables, has left the soil bare without vegetation cover during periods of non-agricultural productivity and reducing the level of evapotranspiration in the studied area.
\end{abstract}

\section{R E S U M O}

A evapotranspiração é um dos principais componentes do balanço de água, sendo de utilidade na quantificação das disponibilidades hídricas regionais. Objetiva-se caracterizar as condições climáticas de evapotranspiração na bacia hidrográfica do rio Ipojuca e realizar a sua interpolação, elaborando mapas representativos da distribuição mensal e anual além das variabilidades de altas e baixas evapotranspiração pelo método da krigagem. Utilizou-se de séries de dados mensais e anuais de precipitação e da temperatura média do ar no período de 1962 - 2018. O método da temperatura foi através do software ®Estima_T. Realizaram a classificação climática segundo Köppen e Thornthwaite. Os dados municipais estimados apresentaram boa acurácia de valores evaporativos e sua consistência é de $95 \%$ de confiabilidade. O desmatamento, as queimadas e o assoreamento dos rios, lagos, lagoas, riachos, córregos e dos lençóis d'água, vem deixando o solo nu sem cobertura vegetal nos períodos da não produtividade agrícola e reduzindo o nível de evapotranspiração na área estudada. 


\section{INTRODUÇÃO}

A necessidade de aumento da produção de alimentos mundial pressiona à expansão de áreas agricultáveis em todo o mundo (FAO, 2012), impulsionando, também, o uso da irrigação nas regiões em que a chuva não atende adequadamente às necessidades hídricas dos cultivos.

A água é essencial para o desenvolvimento das culturas, a falta ou excesso pode influenciar na produção agrícola de determinada localidade ou de uma região) Aa técnica do balanço hídrico $(\mathrm{BH})$ fornece o saldo d'água disponível no solo para o vegetal, ou seja, contabiliza a entrada (precipitação e ou irrigação) e a saída (evapotranspiração potencial), considerando determinada capacidade de água pelo solo (Medeiros et al., 2013).

Evapotranspiração (ETP) é um dos componentes mais importantes do ciclo hidrológico, afetando o equilíbrio de água na superfície da Terra. É também uma das variáveis meteorológicas que é muito aplicada à tomada de decisão em hidrologia, agroecologia, irrigação e outras áreas afins (FU et al., 2009; RODERICK et al., 2009). Resultados demonstram que a magnitude das tendências evapotranspiradas são fatores determinantes, que variam muito de região para região. Estudos adicionais sobre a evapotranspiração e registros em diferentes regiões dos países tropicais são sem dúvidas úteis para fornecer mais evidências e entendermos melhor a variabilidade e a tendência da evapotranspiração global.

Costa et al. (2015) avaliaram a variação da evaporação no tanque classe "A" na cidade de Teresina-PI, em três décadas e meia, e realizaram comparações com as mudanças na urbanização ocorrida em tal período, encontrando alterações nos índices evaporativos em face das modificações antrópicas no espaço. O empecilho ao vento devido ao crescimento horizontal está contribuindo para a redução da evaporação, o contrário ocorre quando chove, não havendo escoamento superficial e ao término da precipitação os índices evaporativos ocorrem em maiores proporções devido à troca de calor Verificaram-se as oscilações de menores e maiores valores ocorridos, com destaque para as décadas 19761985 e 1986-1995 que apresentaram as menores variações. A década de 2006-2011 no mês de outubro apresentou a maior flutuação dos períodos estudados.

Mcvicar et al. (2012) mostraram em seus estudos que as principais causas potenciais da redução da evaporação se evidenciam com as diminuições generalizadas nos índices da temperatura do ar, da radiação solar e das mudanças associadas ao déficit de pressão de vapor e velocidade do vento. $\mathrm{O}$ ar aquecido próximo às plantas transfere energia para a cultura na forma de fluxo de calor sensível, aumentando as taxas evapotranspiratórias.
A evapotranspiração é uma componentes importantes, e de grande utilidade na climatologia, classificações climáticas ou para a quantificação das disponibilidades hídricas regionais (Souza et al., 2011). Segundo o autor a evapotranspiração é importante para o dimensionamento de sistemas e manejo da água de irrigação, requerendo estudos, avaliações e ajustes para sua correta utilização.

Medeiros et al. (2014) analisando as oscilações evapotranspiradas no município de Campina Grande - PB observaram que a ETP anual foi de $1.076,8 \mathrm{~mm}$, com variações de $105,4 \mathrm{~mm}$ no mês de dezembro a $71,3 \mathrm{~mm}$ no mês de agosto. Estas oscilações foram provocada por alta intensidade da radiação solar, rajada de ventos, cobertura de nuvens e variabilidade da temperatura.

Cavalcanti Junior et al. (2011), ao estudar métodos da avaliação da evapotranspiração de referência para as condições do semiárido Nordestino, afirmaram que o consumo hídrico das culturas pode ser determinado através de medições de campo e/ou com a utilização de equações. No campo são realizadas as medições diretas e estas muitas vezes requerem operação dos equipamentos sofisticados e caros, o que inviabiliza sua utilização. Assim, os pesquisadores têm recorrido a equações empíricas por serem práticas e viáveis de serem usadas em manejo de irrigação.

A krigagem é um método geoestatístico que estimativa valores variáveis espalhados no espaço, com dados adjacentes considerados interdependentes pela análise variográfica Pires et al. (2006). As técnicas geoestatísticas podem ser usadas para descrever e oferecer modelos padrões espaciais, além de predizer valores em locais não amostrados segundo Andriotti (2009). Yamamoto et al. (2015) asseguram que a estimativa geoestatística tem por objetivo a modelagem do fenômeno espacial, ou seja, determinar a distribuição e variabilidade de interesse no estudo. Carvalho et al., 2012 mostraram que A krigagem ordinária é um método geoestatístico univariado que tem sido muito utilizada por sua eficiência na interpolação de dados pluviométricos (Carvalho et al., 2012). Uma correlação fraca pode fornecer resultados muito similares entre krigagem e cokrigagem, conforme verificado por Rocha et al. (2012), ao analisarem a influência de uma variável secundária como função da correlação com a variável principal, para a cokrigagem colocalizada.

A krigagem é avaliada aplicada como metodologia de interpolação onde se utilizam os dados tabulados e a disposição geográfica para os cálculos, utilizando o princípio da Primeira Lei de Geografia de Tobler, que descreve que as unidades de análise próximas entre si são igualmente parecidas com as unidades distantes. A krigagem utiliza funções 
matemáticas unindo pesos maiores nas posições próximas aos pontos amostrais e pesos menores nas posições distantes, criando assim novos pontos interpolados com base nessas combinações lineares de dados, (Jakob, 2012). Ribeiro et al. (2011) utilizaram o modelo da Krigagem para a interpolação dos dados do nível estático na aquisição da distância do nível da água subterrânea.

Diante da necessidade de se obter informações a respeito da variável evapotranspiração, tem-se como objetiva estimar e mapear as oscilações da evapotranspiração e suas oscilações espaço temporal mensal, visando à delimitação de regime que caracterize o trimestre com mais e menos poder evapotranspirativo para a bacia hidrográfica do rio Ipojuca, assim como demonstrar a variabilidade da Evaporação (EVP) mês a mês e anual utilizando o método da krigagem.

\section{MATERIAL E MÉTODOS}

A bacia do Rio Ipojuca (BHRI), localiza-se em sua totalidade no Estado de Pernambuco, entre $08^{\circ} 09^{\prime} 50^{\prime \prime}$ e $08^{\circ} 40^{\prime} 20^{\prime \prime}$ de latitude Sul, e $34^{\circ} 57^{\prime} 52^{\prime \prime}$ e $37^{\circ} 02^{\prime} 48^{\prime \prime}$ de longitude Oeste. Devido à sua conformação alongada no sentido oeste-leste, a bacia tem posição estratégica no espaço estadual, servindo de grande calha hídrica de ligação entre a Região Metropolitana do Recife e a região do Sertão do Estado. (CPRN, 2000). Os trechos superior, médio e submédio da bacia estão localizados nas regiões do Sertão e Agreste do Estado, enquanto que o trecho inferior tem a maior parte de sua área situada na zona da Mata Pernambucana, incluindo a faixa litorânea, limita-se ao norte, com a bacia do rio $\mathrm{Ca}$ pibaribe, grupo de bacias de pequenos rios litorâneos e com o Estado da Paraíba; ao sul, com a bacia do Rio Sirinhaém; a leste, com o Oceano Atlântico; e, a oeste, com as bacias dos Rios Ipanema e Moxotó e o Estado da Paraíba (Figura 1).

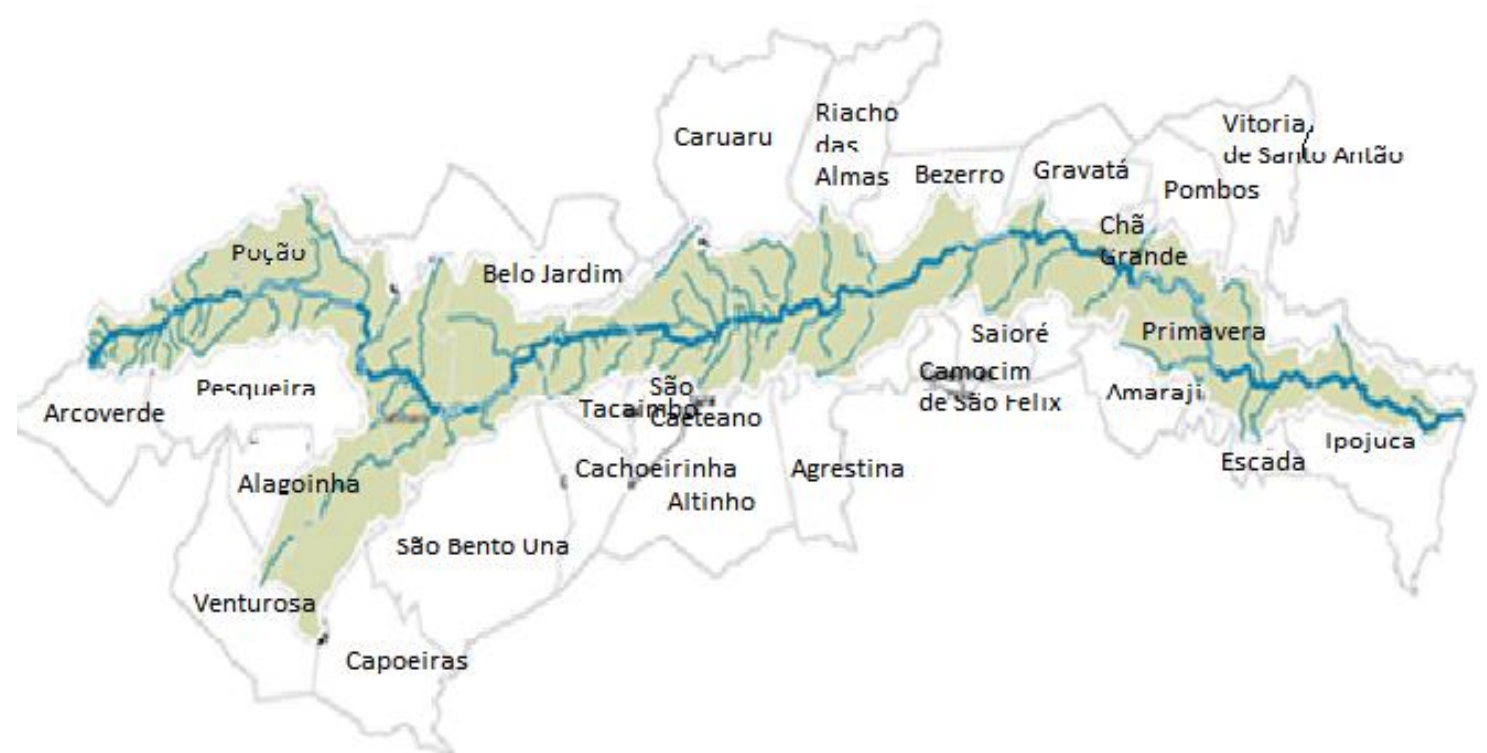

Figura 1 - Perfil da bacia hidrografia do rio Ipojuca e municípios de entorno (Fonte: Medeiros, 2019).

\section{Dados e clima}

A quadra chuvosa se inicia em fevereiro com chuvas de pré-estação (chuvas que antecedem o início da quadra chuvosa) com seu término ocorrendo no final do mês de agosto e podendo se prolongar até a primeira quinzena de setembro. $\mathrm{O}$ trimestre chuvoso centra-se nos meses de maio, junho e julho e os meses secos ocorrem entre outubro, novembro e dezembro. Os fatores provocadores de chuvas nos municípios são a contribuição da Zona de Convergência Intertropical (ZCIT), formação dos vórtices ciclônicos de altos níveis (VCAS), influência dos ventos alísios de nordeste no transporte de vapor e umidade, formações das linhas de instabilidades, orografia e suas contribuições locais formando nuvens e provocando chuvas de moderada a forte, segundo afirmou Medeiros (2016).

Utilizou-se da série mensal e anual de chuva e temperatura média do ar referente ao período de 1962 - 2018 coletados pela Superintendência de Desenvolvimento do Nordeste (Sudene, 1990) e fornecidos pela Agência Pernambucana de Clima e Águas do Estado de Pernambuco (Apac 2019). A utilização dos dados foi procedida de análise no tocante à sua consistência, homogeneização e no preenchimento de falhas em cada série (município a município). O método de preenchimento de falhas 
foi através da média aritmética dos postos vizinhos. O método escolhido foi aplicado por ter-se a disponibilidade de dados de temperatura e chuva em toda a área e contorno da bacia.

Utilizou-se do cenário pluviométrico designado "cenário normal", usando-se a função de distribuição de probabilidade gama incompleta, conforme metodologia proposta por Varejão-Silva et al. (2001). Os balanços hídricos, também, foram calculados segundo a metodologia clássica, usando-se toda a série de dados de chuva disponível, designado por "cenário médio".

No cenário pluviométrico, o computo do balanço hídrico climatológico (BHC) e dos índices climáticos: hídrico e umidade, foram processados conforme Thornthwaite (1948) e Thornthwaite e Mather (1955), assumindo-se a capacidade de água disponível do solo (CAD) igual a $100 \mathrm{~mm}$.

Os valores de evapotranspiração de referência mensal foram estimados pelo método de Thornthwaite (1948), segundo a metodologia apresentada por Gomes et al. (2002).

$$
\begin{gathered}
\mathrm{Ih}=(\mathrm{EXC} / \mathrm{ETP}) \cdot 100 \\
\mathrm{Ia}=(\mathrm{DEF} / \mathrm{ETP}) \cdot 100 \\
\mathrm{Iu}=\mathrm{Ih}-0,6 . \mathrm{Ia}
\end{gathered}
$$

Onde:

Ih: índice hídrico;

Ia: índice de aridez;

Iu: índice de umidade;

ETP: evapotranspiração potencial (mm).

EXC: excedente hídrico oriundo do BHC (mm);

DEF: deficiência hídrica oriunda do BHC (mm);

Os cálculos do balanço hídricos climatológicos (BHC) foram realizados através do programa desenvolvido por Medeiros (2016) levando em conta o modelo de Thornthwaite (1948) e Thornthwaite e Mather (1955).

$\mathrm{Na}$ metodologia adotada utilizou-se dos valores da temperatura média do ar estimados pelo software ®Estima_T (Cavalcanti e Silva, 1994; Cavalcanti et al., 2006). O modelo empírico de estimativa da temperatura do ar é uma superfície quadrática para as temperaturas média, máxima e mínima mensal, em função das coordenadas locais: longitude, latitude e altitude de conformidade com os autores Cavalcanti et al. (2006), dada por:

$$
\begin{gathered}
\mathrm{T}=\mathrm{C} 0+\mathrm{C} 1 \lambda+\mathrm{C} 2 \varnothing+\mathrm{C} 3 \mathrm{~h}+\mathrm{C} 4 \lambda 2+\mathrm{C} 5 \varnothing 2+ \\
\mathrm{C} 6 \mathrm{~h} 2+\mathrm{C} 7 \lambda \varnothing+\mathrm{C} 8 \lambda \mathrm{h}+\mathrm{C} 9 \varnothing \mathrm{h}
\end{gathered}
$$

Onde:

$\mathrm{C} 0, \mathrm{C} 1, \ldots, \mathrm{C} 9$ são as constantes;

$\lambda, \lambda 2, \lambda \varnothing, \lambda \mathrm{h}$

longitude; $\varnothing, \varnothing 2, \lambda \varnothing$

latitude; $h, h 2, \lambda \mathrm{h}, \varnothing \mathrm{h}$ altura.

Utilizou-se ainda da série temporal de temperatura, adicionando a esta a anomalia de temperatura do Oceano Atlântico Tropical (Cavalcanti et al., 2006).

$$
\mathrm{Tij}=\mathrm{Ti}+\mathrm{AATij}
$$

Onde: $\mathrm{i}=1,2,3, \ldots, 12 . ; \mathrm{j}=1950,1951,1952,1953$, ...,2014.

\section{RESULTADOS E DISCUSSÕES}

Na Tabela 1 tem-se a localização dos municípios, seguidamente de suas coordenadas geográficas (latitude, longitude) locais, seguidamente das classificações climáticas segundo Köppen e Thornthwaite. O clima da BHRI segundo a classificação de Köppen (1928; 1931); Thornthwaite e Mather (1948; 1955), estão apresentados na Tabela 1 esta classificação segundo o autor Köppen e os estudos dos autores Medeiros et al. (2018) e Alvares et al. (2014), tem similaridades nas suas classificações.

Sabe-se que os elementos meteorológicos como radiação solar, temperatura do ar, velocidade do vento e pressão de saturação do vapor durante o período seco contribuem para o aumento dos índices evapotranspirativos da área de estudos.

Figura 1 observam-se as variabilidades evapotranspirativas do mês de janeiro para a área em estudo. As oscilações da ETP fluem entre 96 a 146 $\mathrm{mm}$. A região do agreste e da zona da mata setor oeste apresentam as menores incidências de ETP. Nas regiões de Mata Oeste e litoral a ETP fluem entre 126 a $146 \mathrm{~mm}$. Estas flutuações têm contribuições do efeito da brisa marítima, da cobertura da vegetação e da incidência da radiação. Resultados semelhantes foram encontrados por Medeiros (2016) para a bacia hidrográfica do rio Uruçuí Preto $-\mathrm{PI}$. 
Tabela 1 - Localização dos municípios e dos postos pluviométricos seguidamente de suas coordenadas geográficas (latitude, longitude) locais, e sua classificação climática segundo Köppen e Thorntwaite.

\begin{tabular}{|c|c|c|c|c|}
\hline \multirow{2}{*}{ Municípios } & \multirow{2}{*}{ Longitude } & \multirow{2}{*}{ Latitude } & \multicolumn{2}{|c|}{ Classificação } \\
\hline & & & Köppen & Thornthwaite \\
\hline Arcoverde & $-37,0556$ & $-8,4336$ & As & $\mathrm{C}_{1} \mathrm{~B}_{4}{ }_{4} \mathrm{~S}_{2} \mathrm{a}^{\prime}$ \\
\hline Agrestina & $-35,9536$ & $-8,4578$ & As & $\mathrm{C}_{1} \mathrm{~A}^{\prime} \mathrm{S}_{2} \mathrm{a}^{\prime}$ \\
\hline Alagoinha & $-36,7739$ & $-8,4661$ & As & $\mathrm{C}_{1} \mathrm{~B}^{\prime}{ }_{4} \mathrm{~S}_{2} \mathrm{a}^{\prime}$ \\
\hline Altinho & $-36,0597$ & $-8,4906$ & As & $\mathrm{DB}_{4}{ }_{4} \mathrm{~S}_{2} \mathrm{a}^{\prime}$ \\
\hline Amaraji & $-35,4472$ & $-8,3778$ & Am & $\mathrm{C}_{1} \mathrm{~A}^{\prime} \mathrm{S}_{2} \mathrm{a}^{\prime}$ \\
\hline Belo Jardim & $-36,4208$ & $-8,3333$ & As & $\mathrm{C}_{2} \mathrm{~B}_{4}{ }_{4} \mathrm{Sa}^{\prime}$ \\
\hline Bezerros & $-35,7528$ & $-8,2433$ & As & $\mathrm{C}_{1} \mathrm{~B}^{\prime}{ }_{4} \mathrm{~S}_{2} \mathrm{a}^{\prime}$ \\
\hline Cachoeirinha & $-36,2375$ & $-8,4839$ & As & $\mathrm{C}_{2} \mathrm{~B}^{\prime}{ }_{4} \mathrm{~S}_{2} \mathrm{a}^{\prime}$ \\
\hline Caruaru & $-35,9158$ & $-8,2383$ & $\mathrm{BSh}$ & $\mathrm{C}_{1} \mathrm{~B}_{4}^{\prime} \mathrm{S}_{2} \mathrm{a}^{\prime}$ \\
\hline Chã Grande & $-39,2361$ & $-7,7211$ & As & $\mathrm{C}_{1} \mathrm{~A}^{\prime} \mathrm{S}_{2} \mathrm{a}^{\prime}$ \\
\hline Escada & $-35,2333$ & $-8,3667$ & Am & $\mathrm{C}_{2} \mathrm{~A}^{\prime} \mathrm{Sa}^{\prime}$ \\
\hline Gravatá & $-35,5431$ & $-8,2006$ & As & $\mathrm{C}_{1} \mathrm{~A}^{\prime} \mathrm{S}_{2} \mathrm{a}^{\prime}$ \\
\hline Ipojuca & $-35,0058$ & $-8,5144$ & $\mathrm{Am}$ & $\mathrm{C}_{1} \mathrm{~A}^{\prime} \mathrm{S}_{2} \mathrm{a}^{\prime}$ \\
\hline Pesqueira & $-36,6972$ & $-8,3531$ & As & $\mathrm{C}_{1} \mathrm{~B}^{\prime}{ }_{4} \mathrm{~S}_{2} \mathrm{a}^{\prime}$ \\
\hline Poção & $-36,7053$ & $-8,1836$ & As & $\mathrm{C}_{1} \mathrm{~B}_{4}^{\prime} \mathrm{S}_{2} \mathrm{a}^{\prime}$ \\
\hline Pombos & $-35,3961$ & $-8,1386$ & As & $\mathrm{C}_{1} \mathrm{~A}^{\prime} \mathrm{S}_{2} \mathrm{a}^{\prime}$ \\
\hline Primavera & $-35,3475$ & $-8,3483$ & As & $\mathrm{C}_{1} \mathrm{~A}^{\prime} \mathrm{S}_{2} \mathrm{a}^{\prime}$ \\
\hline Riacho das Almas & $-35,8592$ & $-8,1381$ & As & $\mathrm{C}_{2} \mathrm{~B}_{4}{ }_{4} \mathrm{Sa}^{\prime}$ \\
\hline Sairé & $-35,7089$ & $-8,3267$ & As & $\mathrm{C}_{2} \mathrm{~B}_{4}{ }_{4} \mathrm{Sa}^{\prime}$ \\
\hline Sanharó & $-36,5664$ & $-8,3639$ & As & $\mathrm{C}_{1} \mathrm{~B}_{4}{ }_{4} \mathrm{Sa}^{\prime}$ \\
\hline São Caitano & $-36,1375$ & $-8,3283$ & $\mathrm{BSh}$ & $\mathrm{C}_{1} \mathrm{~B}_{4}{ }_{4} \mathrm{Sa}^{\prime}$ \\
\hline São Bento do Una & $-36,46$ & $-8,5281$ & As & $\mathrm{C}_{1} \mathrm{~B}_{4}^{\prime} \mathrm{S}_{2} \mathrm{a}^{\prime}$ \\
\hline Tacaimbó & $-38,1533$ & $-9,1089$ & As & $\mathrm{C}_{1} \mathrm{~B}_{4}^{\prime} \mathrm{S}_{2} \mathrm{a}^{\prime}$ \\
\hline Venturosa & $-38,9694$ & $-7,9286$ & As & $\mathrm{C}_{1} \mathrm{~B}_{4}{ }_{4} \mathrm{~S} 2 \mathrm{a}^{\prime}$ \\
\hline Vitória de Santo Antão & $-35,6347$ & $-8,8383$ & As & $\mathrm{C}_{1} \mathrm{~A}^{\prime} \mathrm{Sa}^{\prime}$ \\
\hline
\end{tabular}

Fonte: Medeiros (2019).

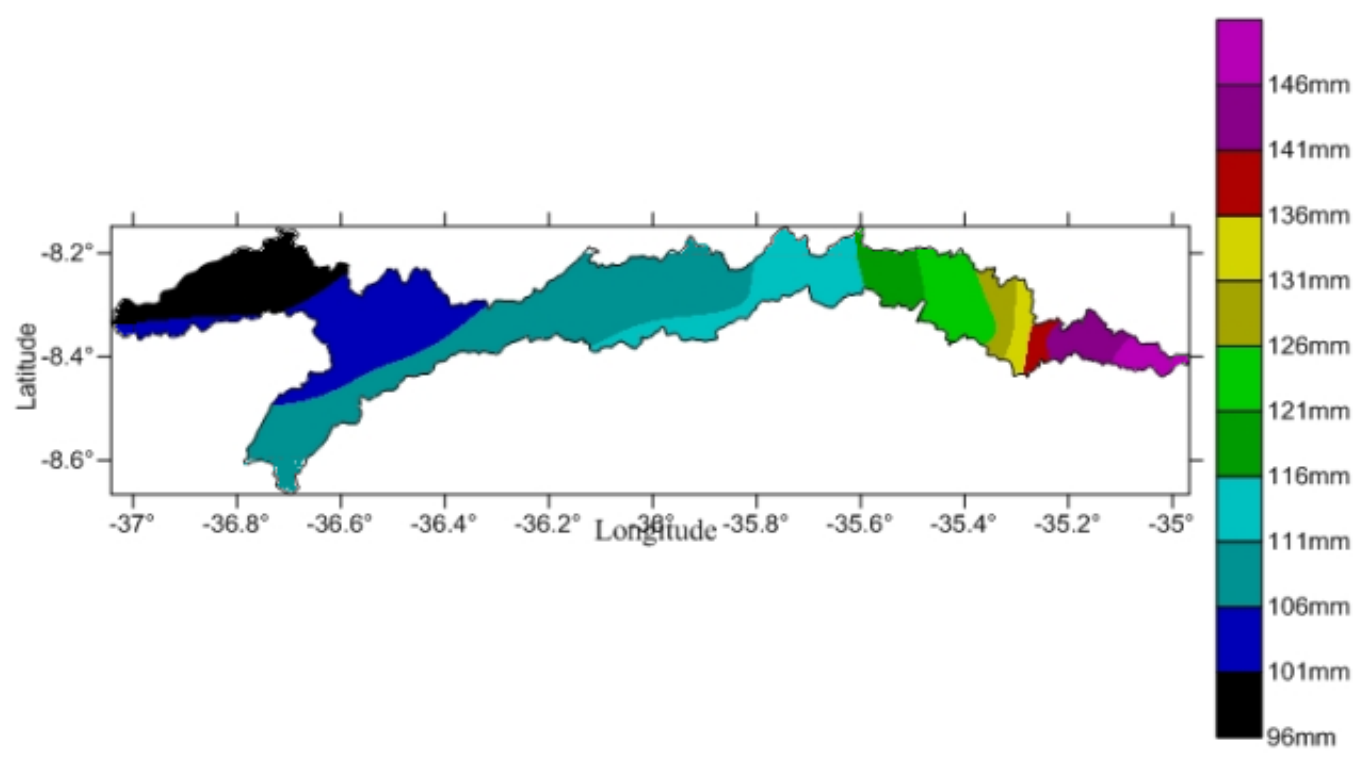

Figura 1 - Evapotranspiração do mês de janeiro para a área da BHRI (Medeiros, 2019).

Nas regiões do litoral e Zona da Mata registramse os maiores índices evaporativos com flutuações entre $116 \mathrm{~mm}$ a $136 \mathrm{~mm}$. Na região do agreste as flutuações evaporativas foram de $101 \mathrm{~mm}$ a 116 $\mathrm{mm}$. Nas regiões do sertão e alto sertão registra-se índices evaporativos de menores oscilações devido às variabilidades do período chuvoso.
As flutuações da evapotranspiração na BHRI registram reduções evapotranspirativas no sentido oeste-este (Figura 2) para o mês de fevereiro. Nos setores do Alto Sertão e Sertão ocorrem os menores valores de ETP devido à influência do período chuvoso. Nas regiões do Agreste, Zona da Mata e Litoral os índices evaporativos fluem entre $106 \mathrm{~mm}$ 
$136 \mathrm{~m}$, estas variabilidades estão interligadas aos sistemas atuantes de meso e micro escala e as contribuições locais como ausência de nuvem, velocidade do vento moderada, maior incidência de radiação solar entre outros fatores como vento, nebulosidade auxiliam os índices evaporativos.

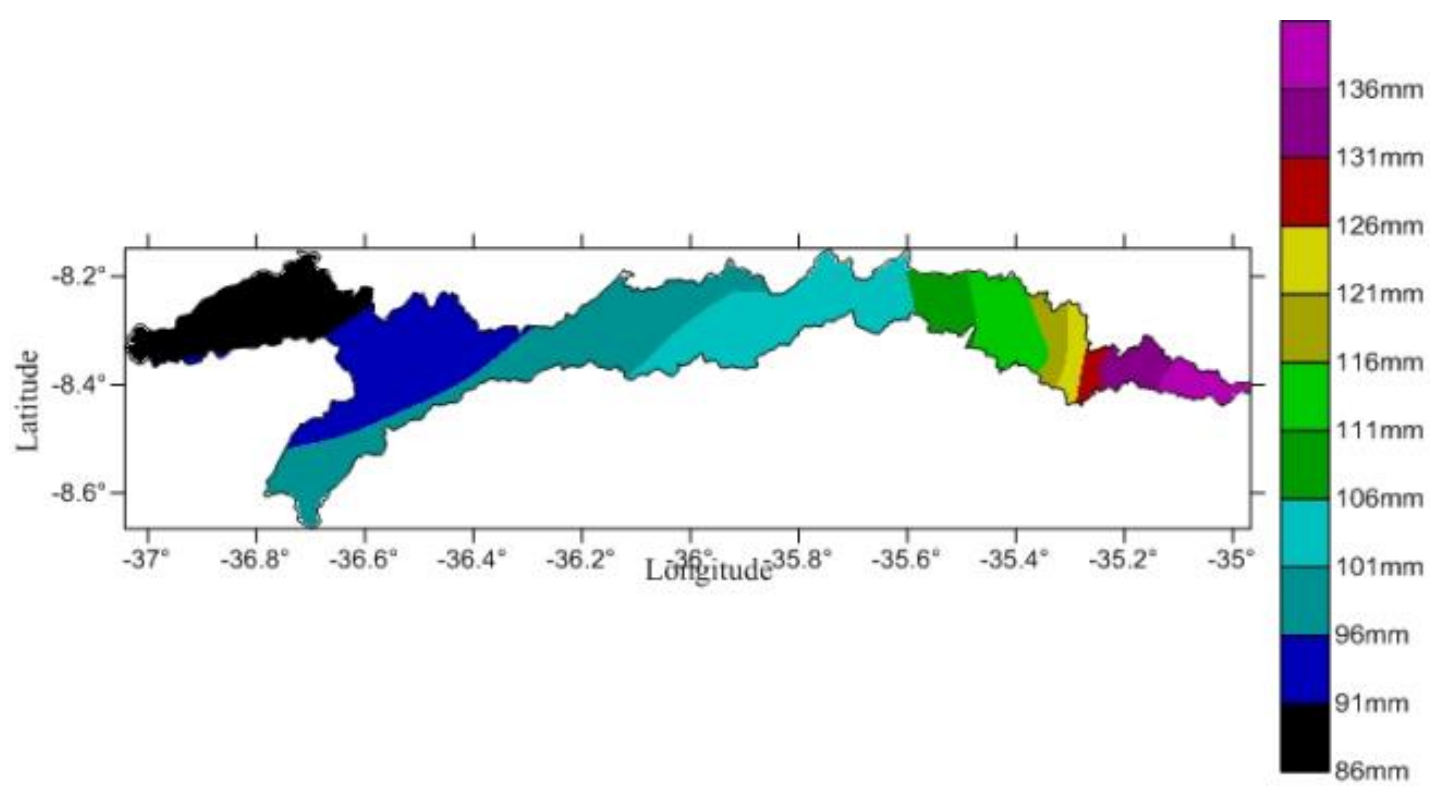

Figura 2 - Evapotranspiração do mês de fevereiro para a área da BHRI (Fonte: Medeiros, 2019).

O mês de março (Figura 3) mostra a variabilidade da evapotranspiração na bacia hidrográfica do rio Ipojuca onde se registra decréscimo evaporativo no sentido oeste-este. Entre Sertão e alto sertão apresentam memores índices evaporativos, região do agreste, Zona da Mata e Litoral registra-se flutuações evaporativas fluindo de $109 \mathrm{~mm}$ a $144 \mathrm{~mm}$.

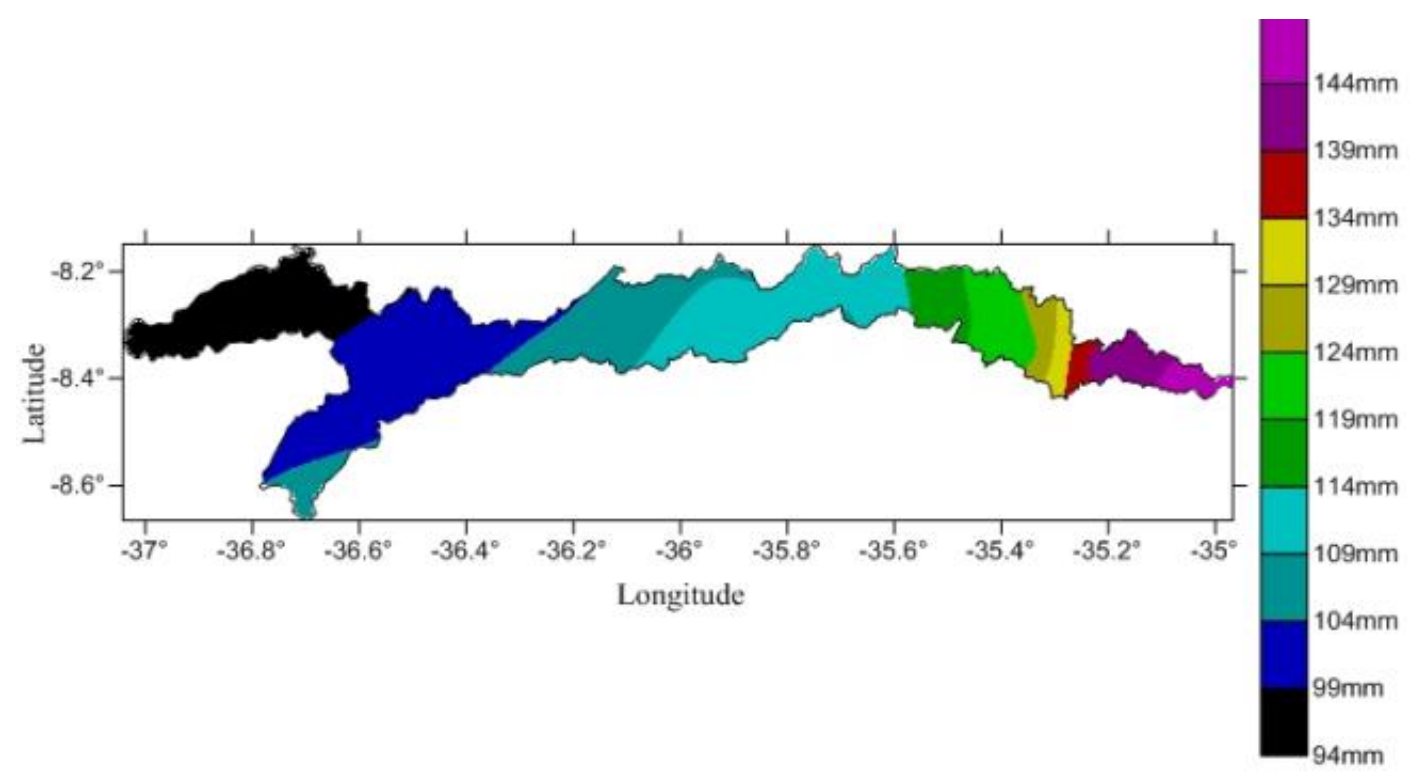

Figura 3 - Evapotranspiração do mês de março para a área da BHRI (Fonte: Medeiros, 2019).

No mês de abril (Figura 4) os índices evaporativos oscilam entre 80 a $130 \mathrm{~mm}$. Estas oscilações são ocasionadas pelas ações do período chuvoso em todo o Estado. Na região do Sertão e Alto Sertão registra-se poderes evaporativos de 80 a $105 \mathrm{~mm}$. Nas regiões do Agreste, Zona da Mata e Litoral as variabilidades evaporativas fluem entre 105 a 130 $\mathrm{mm}$. 


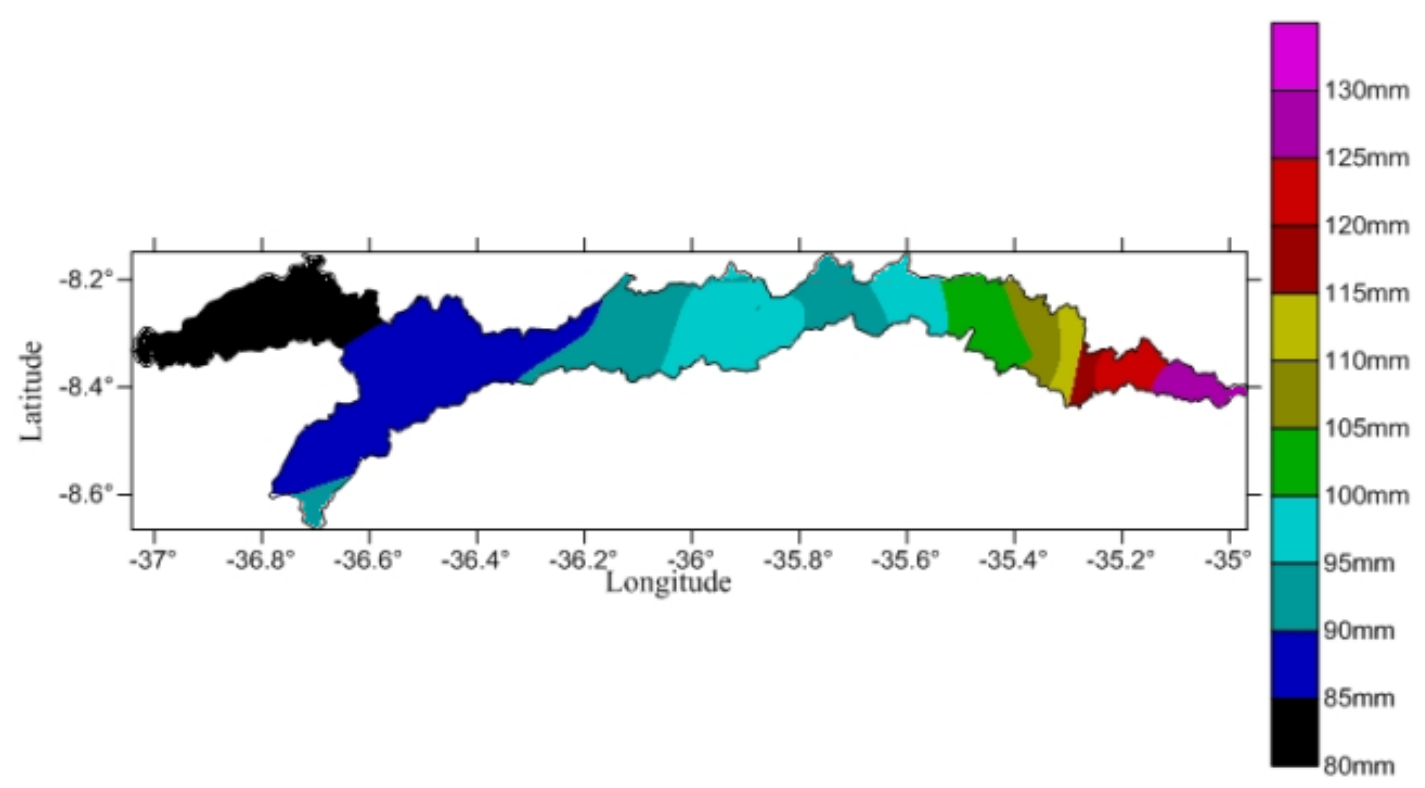

Figura 4 - Evapotranspiração do mês de abril para a área da BHRI (Fonte: Medeiros, 2019).

Com oscilações evaporativas fluindo entre 72 a $112 \mathrm{~mm}$ para o mês de maio (Figura 5) destacamse reduções no sentido oeste-leste. Nas regiões do Alto Sertão e Sertão têm-se os menores índices evaporativos auxiliados pela quadra chuvosa. Nas regiões do Agreste, Zona da Mata e Litoral os índices evaporativos fluem entre 87 a $112 \mathrm{~mm}$ e estas flutuações tem auxílios das chuvas de pré-estação que ocasionam chuvas de intensidades moderadas em curto intervalo de tempo e auxilia na redução da ETP.

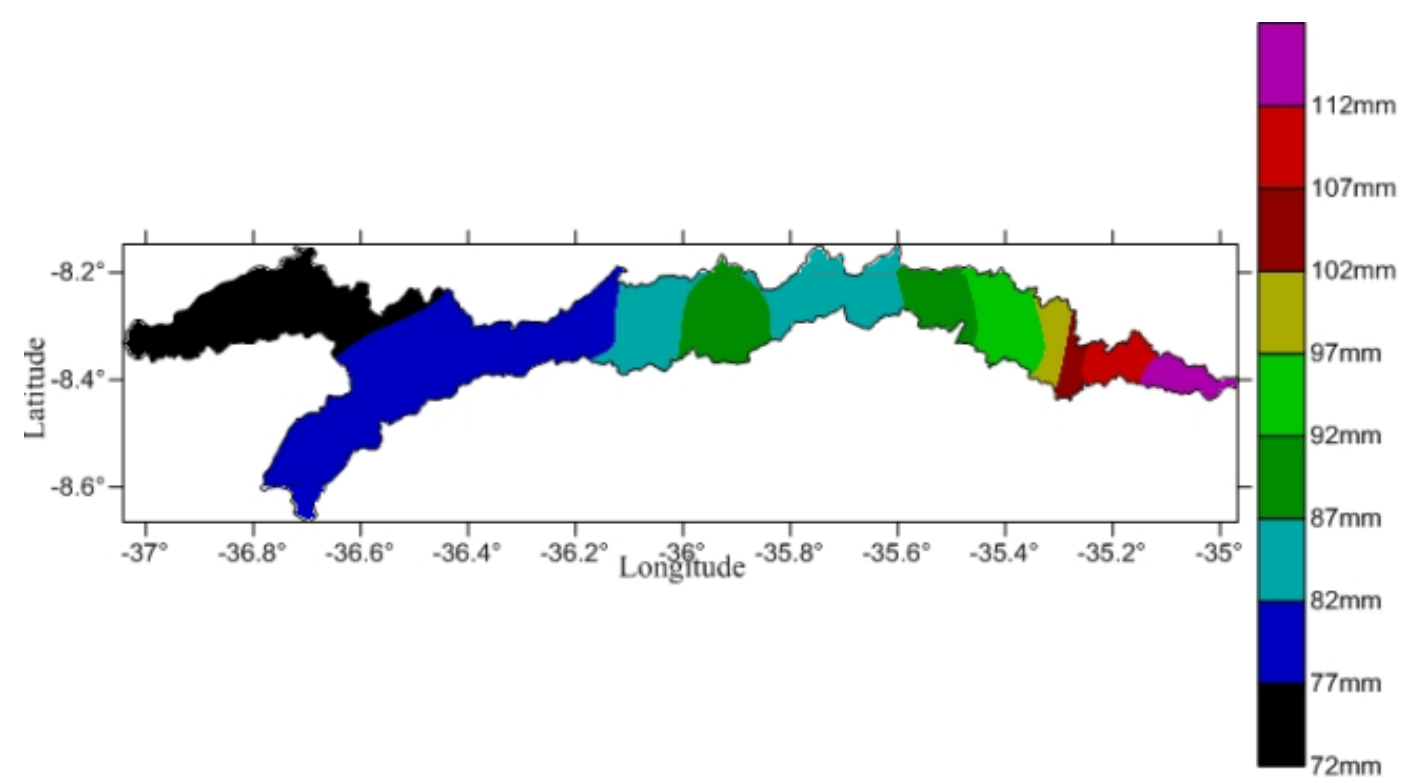

Figura 5 - Evapotranspiração do mês de maio para a área da bacia do rio Ipojuca - PE (Fonte: Medeiros, 2020).

Figura 6 tem a distribuição de evapotranspiração do mês de junho na BHRI. Observa-se que na zona da Mata e do Litoral e no setor Este do Agreste ocorrem às altas taxas evapotranspiradas, no setor oeste da região do Agreste e nas regiões do Sertão e Alto Sertão registram-se as baixas taxas evapotranspirativas. Observa-se um acréscimo evaporativo no sentido Oeste/Leste. Na região central do estado tem-se um núcleo de ETP isolado e uma pequan área de evapotranspiração ao sul da citada área. 


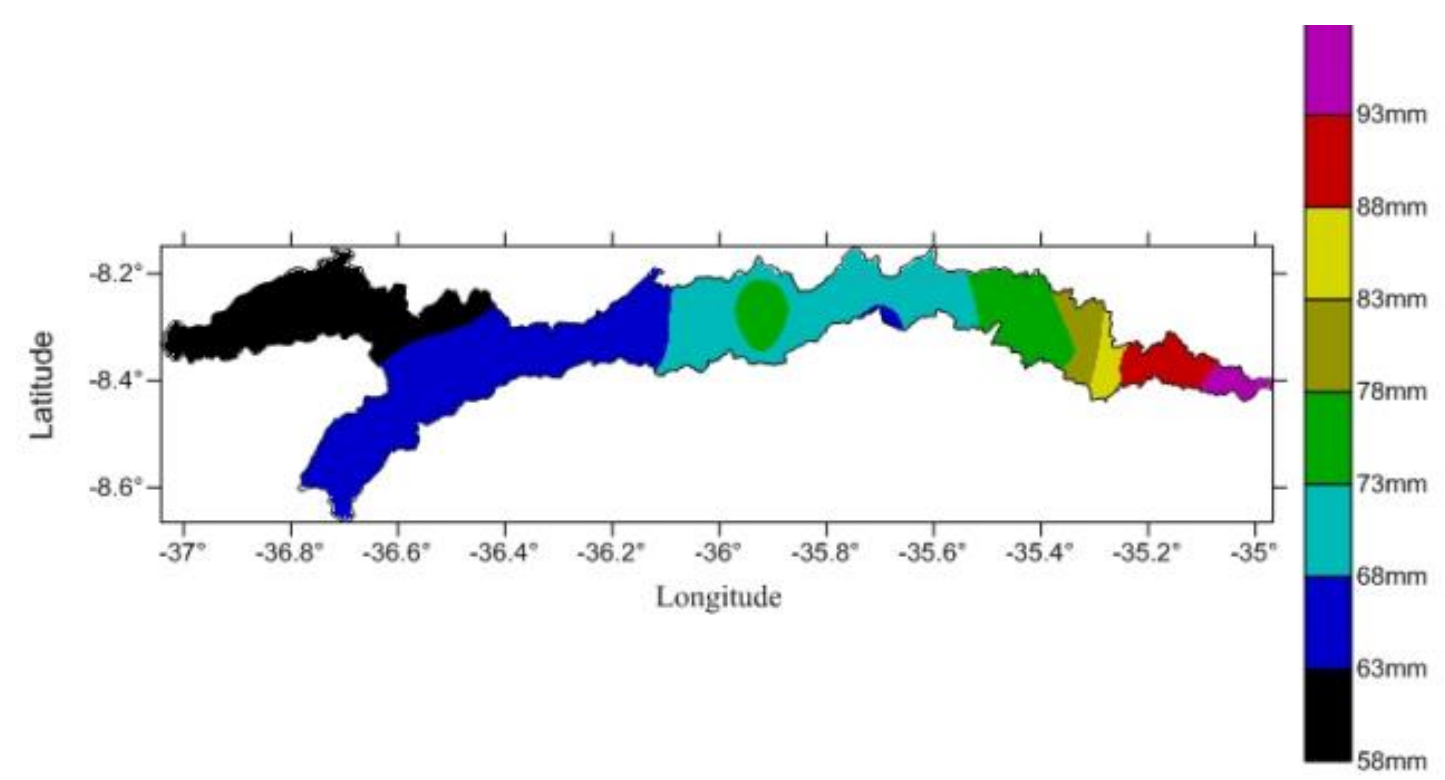

Figura 6 - Evapotranspiração do mês de junho para a área da BHRI (Fonte: Medeiros, 2019).

O estudo de Stone et al. (2010) concluem que os padrões de desenvolvimento urbano em expansão como a verticalização urbana, alteração da área vegetal, compactação do solo com a pavimentação, aterramento de lagoas, eutrofização dos espelhos da água têm impacto negativo sobre a cobertura de vegetação regional, aumentando a taxa evapotranspirativa .
Figura 7 tem-se os índices evapotranspirado do mês de julho para a área de estudo. A ETP oscila entre $56 \mathrm{~mm}$ a $86 \mathrm{~mm}$. No setor litoral e Zona da Mata registram-se os maiores índices evapotranspirados, nas regiões do sertão e alto sertão registra-se as menores taxa evapotranspiradas. Área isolada de $61 \mathrm{~mm}$ foram registrado na região central do Estado.

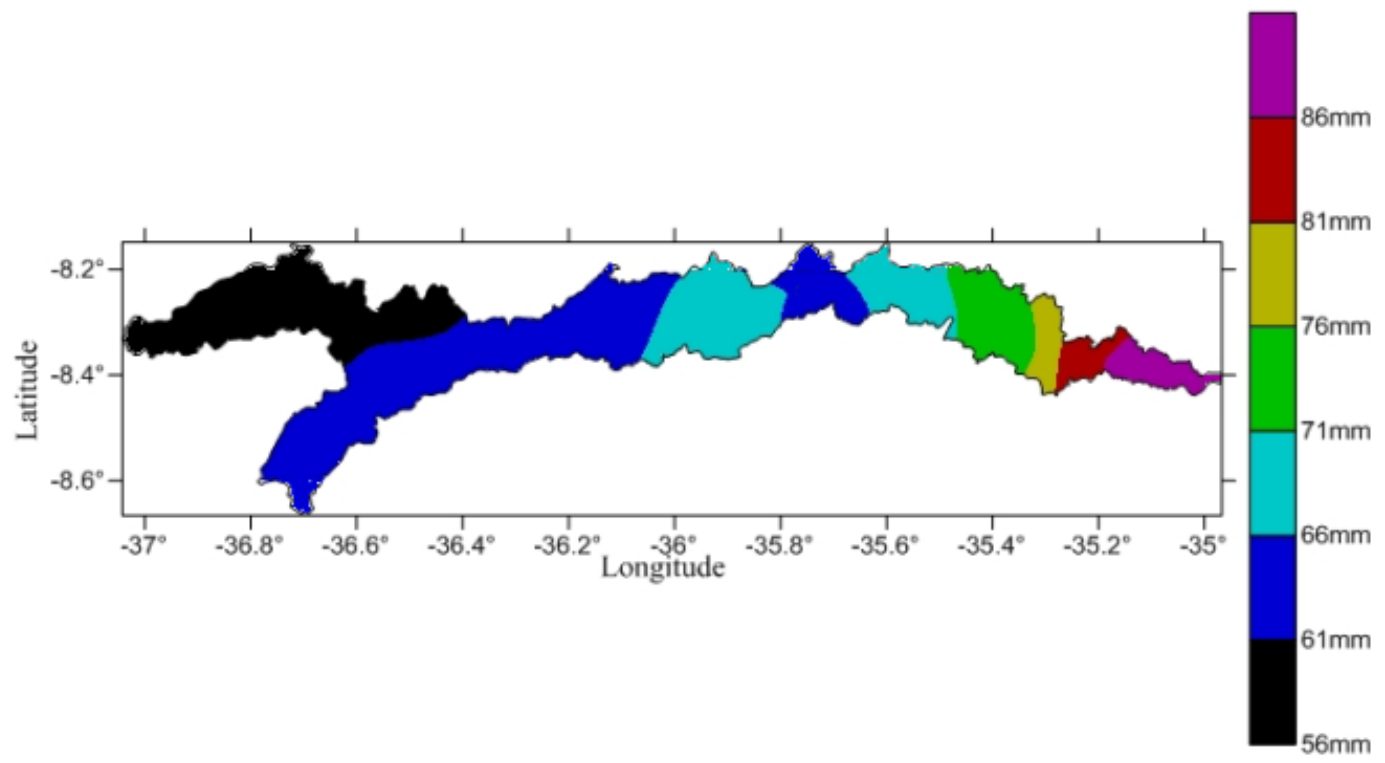

Figura 7 - Evapotranspiração do mês de julho para a área da bacia do rio Ipojuca - PE (Fonte: Medeiros, 2019).

Com oscilações evapotranspiradas variando de $58 \mathrm{~mm}$ a $88 \mathrm{~mm}$ no mês de agosto (Figura 8 ) registram-se aumentos no sentido Oeste-Leste, nas regiões: Alto Sertão, Sertão e parte Oeste do Agreste, têm-se valores evapotranspirados oscilando entre $58 \mathrm{~mm}$ a $68 \mathrm{~mm}$. Na parte este do Agreste, na Zona da Mata e Litoral os índices evaporativos fluíram entre $68 \mathrm{~mm}$ a $88 \mathrm{~mm}$. 


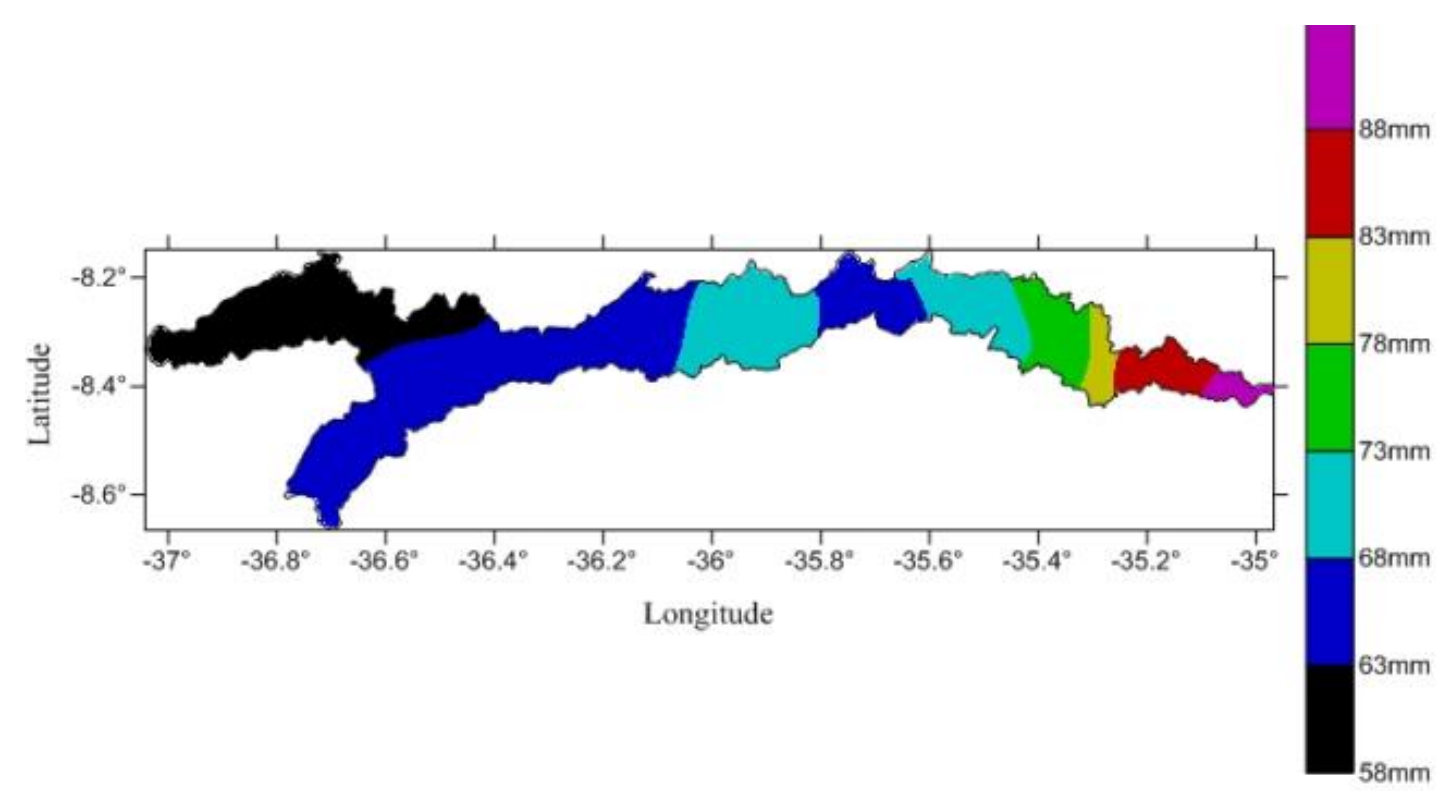

Figura 8 - Evapotranspiração do mês de agosto para a área da bacia do rio Ipojuca - PE (Fonte: Medeiros, 2019).

Com flutuações evapotranspirativas entre 71 a 96 mm como observada na Figura 9. As flutuações evaporativas nas regiões do Alto Sertão, Sertão e Agreste fluem entre 71 a $81 \mathrm{~mm}$, já a região da
Zona da Mata e Litoral os índices de ETP oscilaram entre de 86 a $96 \mathrm{~mm}$. Estas flutuabilidades estão de acordo com os estudos de Medeiros et al. (2016) para a bacia hidrográfica do rio Uruçuí Preto.

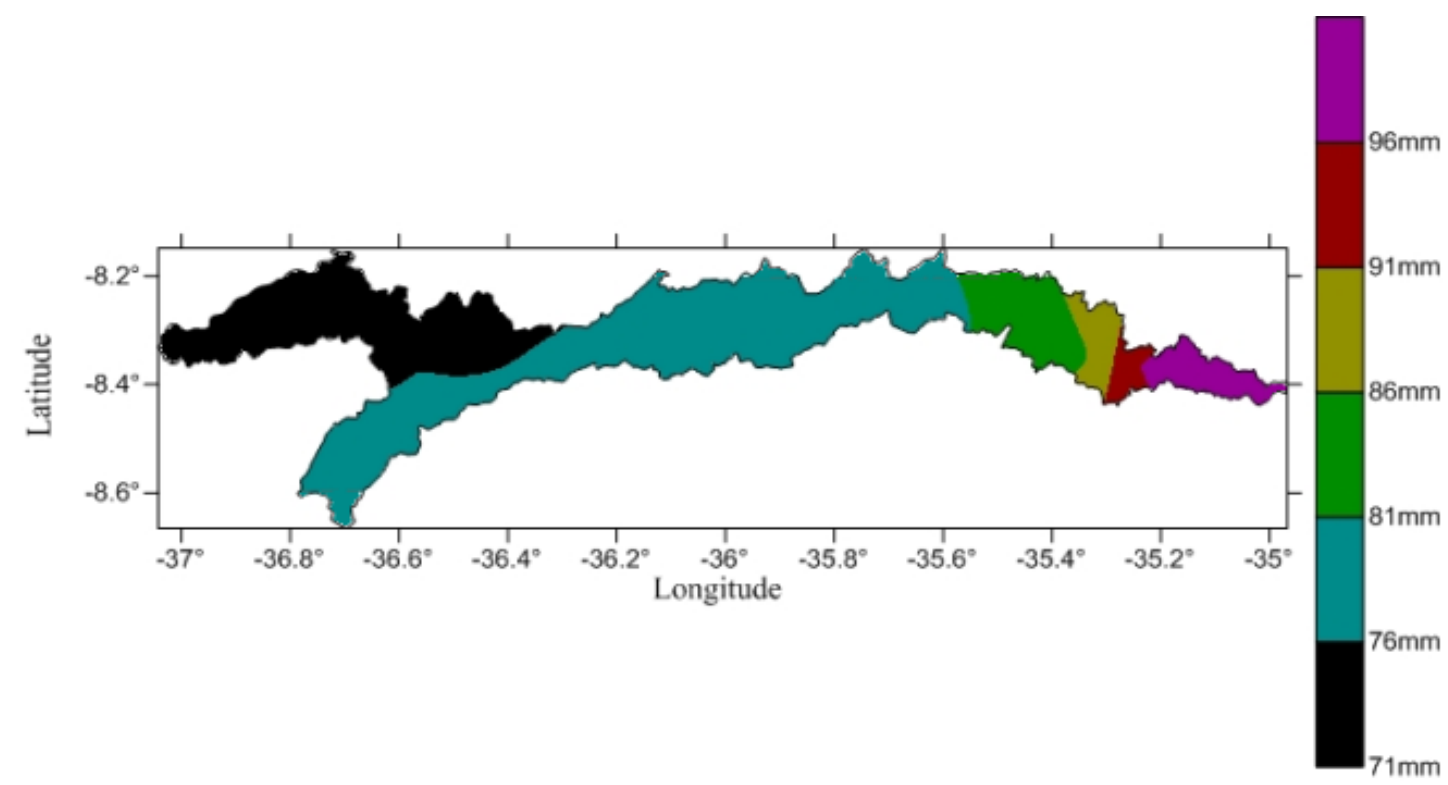

Figura 9 - Evapotranspiração do mês de setembro para a área da bacia do rio Ipojuca - PE (Fonte: Medeiros, 2019).

Na figura 10 observamos a distribuição da evapotranspiração do mês de outubro para a área da bacia do rio Ipojuca - PE. Como o solo em sua grande parte está sem capacidade de campo os índices evaporativos praticamente são das arborizações que são escassas na área. Nas regiões do Alto Sertão, Sertão e parte leste do Agreste têm-se flutuações evapotranspirativas oscilando entre 84 a $99 \mathrm{~mm}$. Na parte este da região do Agreste, Zona da Mata e Litoral os índices evapotranspirativos oscilam entre 99 a $124 \mathrm{~mm}$. Destaca que da parte este do Agreste, Zona da Mata e Litoral ocorrem chuvas isoladas de magnitudes variadas e tem-se as contribuições dos fatores como brisa marítima/terrestre, linha de instabilidade e a orografia que ajuda ou auxilia os índices de ETP. 


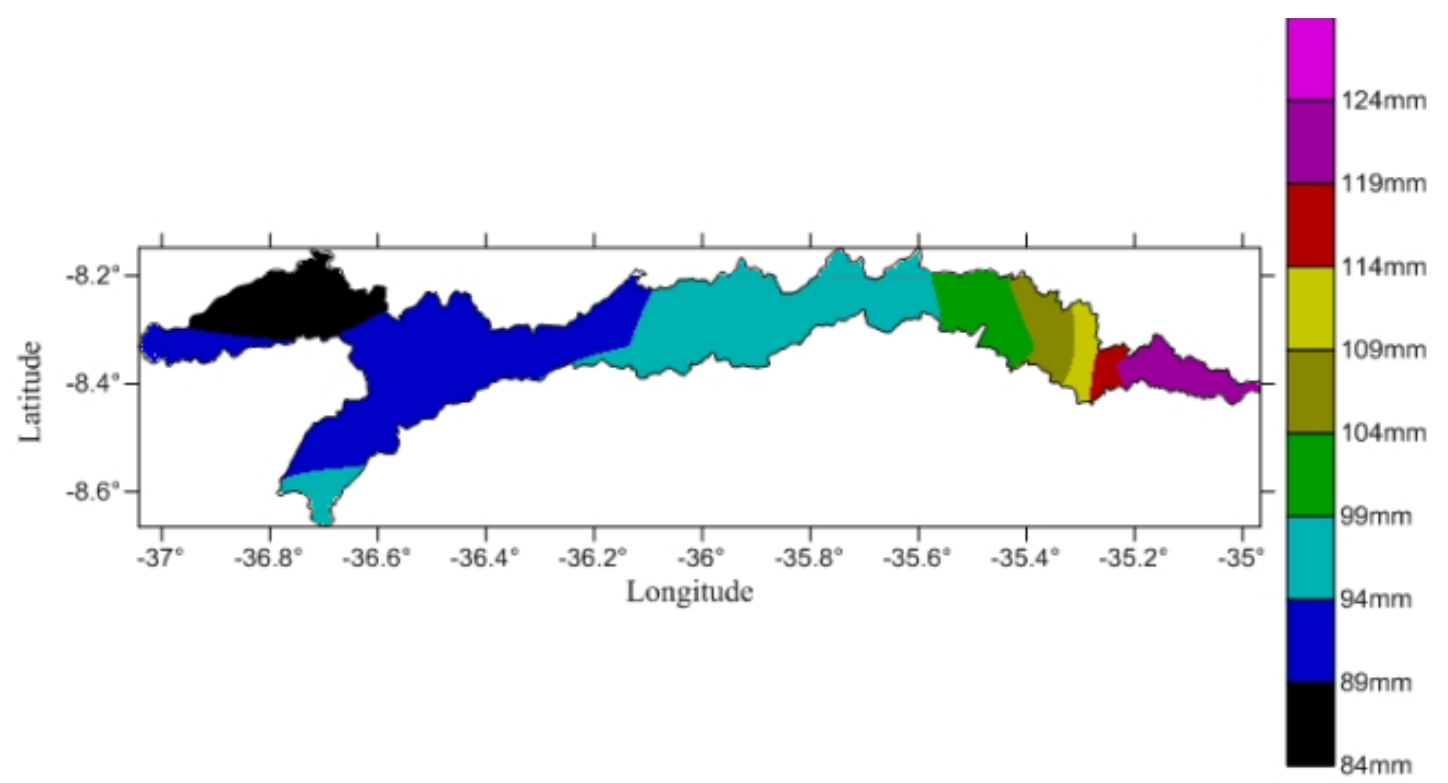

Figura 10 - Evapotranspiração do mês de outubro para a área da bacia do rio Ipojuca - PE (Fonte: Medeiros, 2019).

A figura 11 corresponde às variabilidades evaporativas do mês de novembro na BHRI. Nas regiões do Agreste, Sertão e Alto Sertão têm-se os menores índices evaporativos visto que o mês de novembro é considerado seco em relação aos índices pluviais e o solo encontra-se basicamente sem umidade o que faz a redução da evapotranspiração devido. Na região da Zona da Mata e Litoral registram-se chuvas com índices moderado e isolada, além do mais nestas regiões proximidade do mar e suas contribuições ao aumento de umidade facilitando deste modo maiores índices evaporativos. As menores taxas evaporativas registram-se nas regiões do sertão e alto sertão e os maiores índices evapotranspirativos situa-se no litoral e Zona da Mata pernambucana.

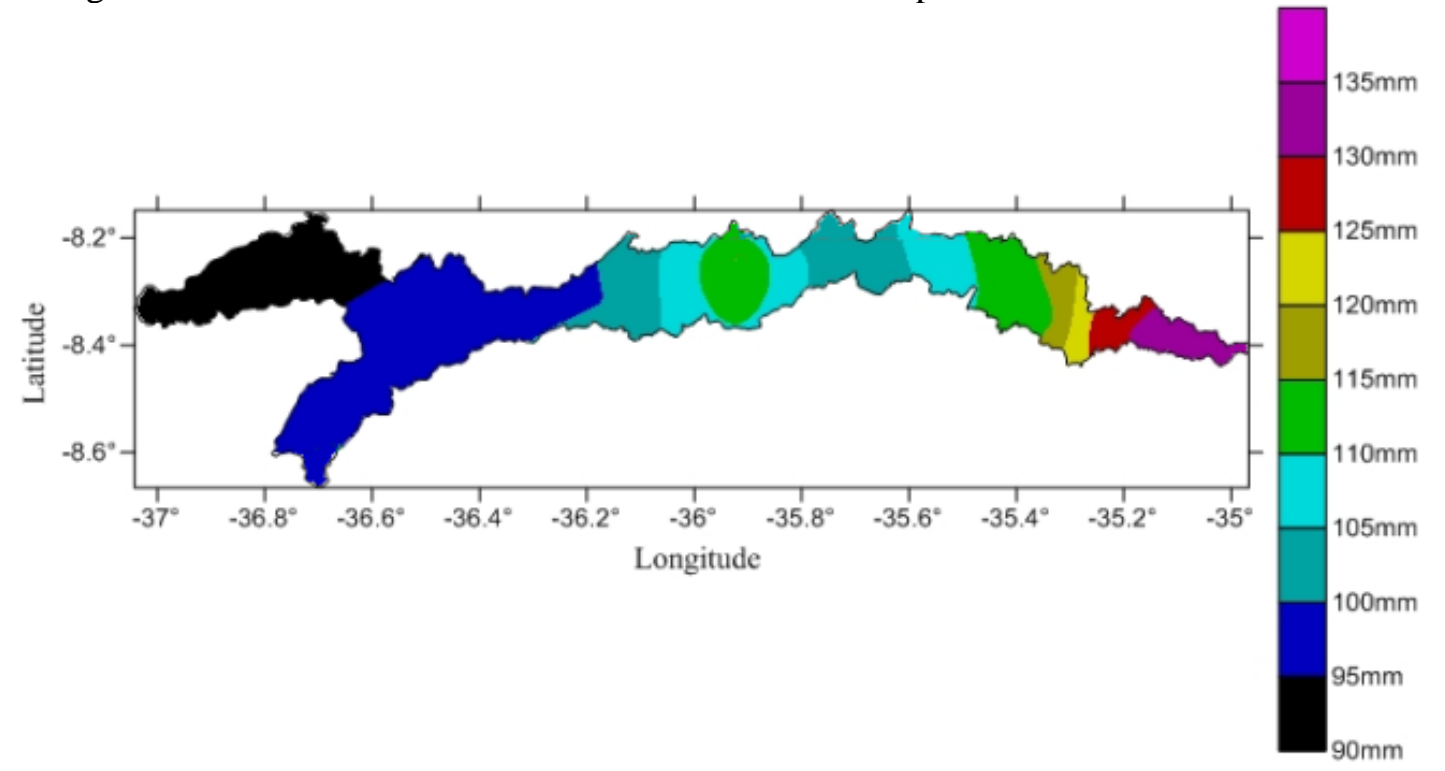

Figura 11 - Evapotranspiração do mês de novembro para a área da bacia do rio Ipojuca - PE (Fonte: Medeiros, 2019).

Devido à escassez dos recursos hídricos, principalmente em regiões semiáridas e de transições, é indispensável aperfeiçoar a utilização da água, para atender às necessidades das culturas irrigadas. A ETP está relacionada às flutuações térmicas, cobertura de nuvens e ventos regionais. A partir de métodos que determinem a evapotranspiração das culturas, podem-se minimizar os desperdícios conforme os autores Esteves et al. (2009) e Sousa et al. (2010). Segundo ainda os autores os índices 
evaporativos da área estudada forma bem superiores as suas médias. Estes artigos vêm a corroborar com os resultados aqui demonstrados.

O mês de dezembro (Figura 12) registrou decréscimo da ETP no sentido Leste-Oeste com oscilações fluindo entre 95 a $155 \mathrm{~mm}$. Nas regiões do litoral, Zona da Mata e agreste a ETP oscila entre 110 a $145 \mathrm{~mm}$. No sertão e alto sertão a ETP oscila entre 95 a $110 \mathrm{~mm}$ estes valores reduzidos são devidos a incidências do período chuvoso ou das chuvas de pré-estação para a região citada.

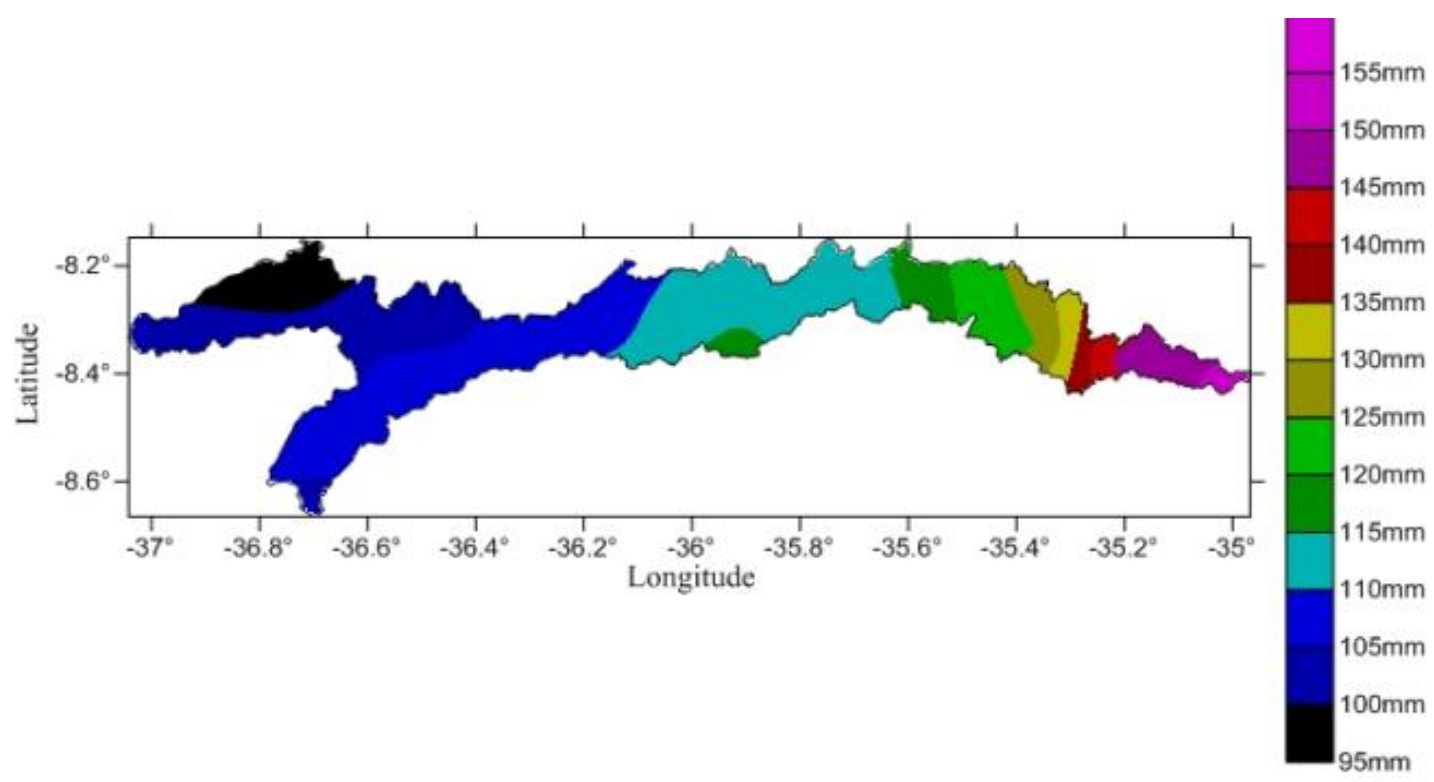

Figura 12 - Evapotranspiração do mês de dezembro para a área da bacia do rio Ipojuca-PE (Fonte: Medeiros, 2019).

Na figura 13 tem-se a distribuição anual da ETP com suas flutuações entre 96 a $151 \mathrm{~mm}$. No setor oeste e na central da bacia registram-se os menores índices evapotranspirados. No setor leste compreendendo o litoral e Zona da Mata tem-se os valores de evapotranspiração elevados. A ETP é crescente de oeste para leste e segue a distribuição do regime de chuva na área em estudo. Na região do agreste a ETP oscilou entre 111 a $126 \mathrm{~mm}$.

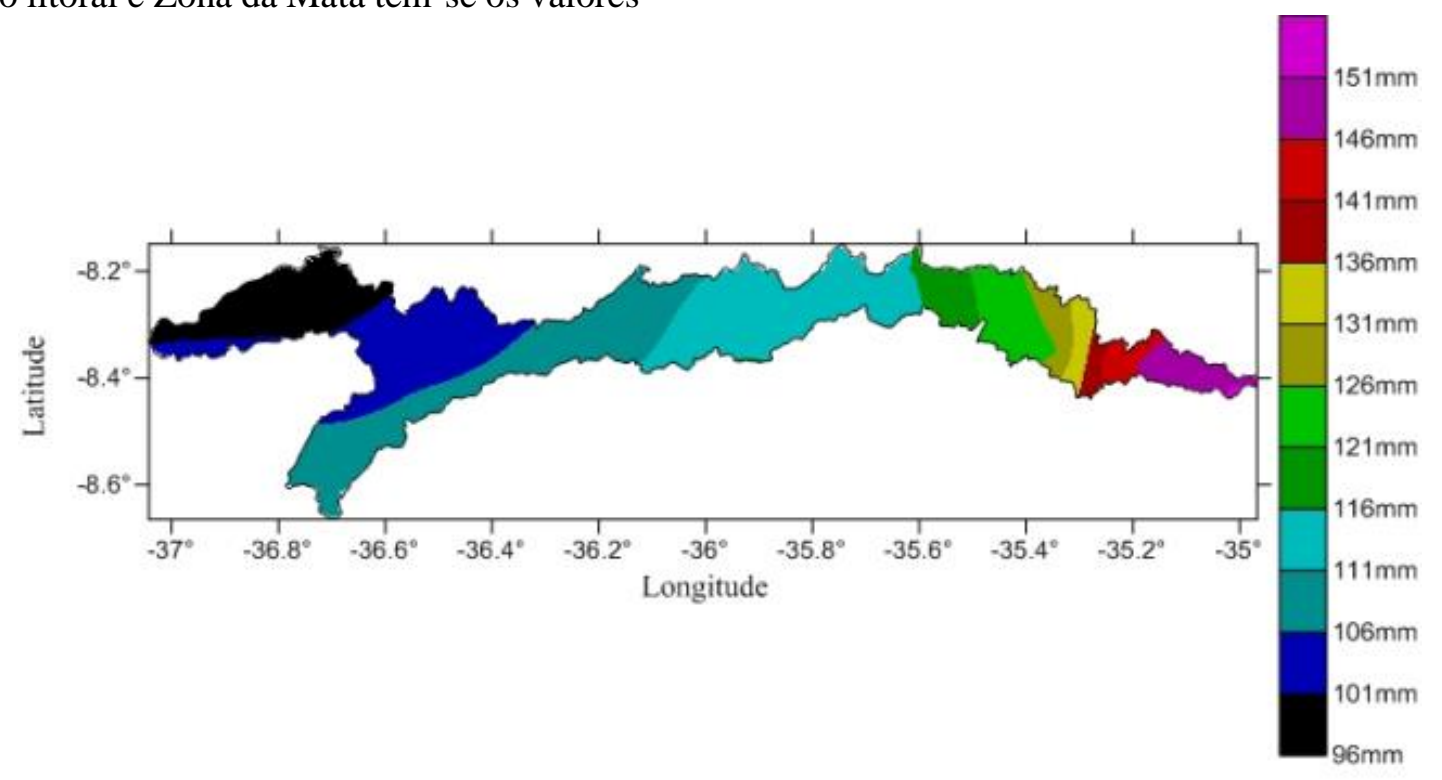

Figura 13 - Evapotranspiração anual para a área da bacia do rio Ipojuca - PE (Fonte: Medeiros, 2019). 
Os meses de novembro, dezembro, janeiro, fevereiro e março correspondem aos meses de maiores taxas evaporativos na área da bacia hidrográfica do rio Ipojuca. As flutuações ocorrem entre 92 a 142 $\mathrm{mm}$. Destaca-se que o aumento evapotranspirado ocorre no sentido oeste leste de acordo com a Figura 14. Destaca-se ainda que nos referidos meses os índices pluviométricos sejam insignificantes para agricultura e represamento de água e que a vegetação se apresenta em sua maioria em ponto de murcha a estressadas devido à falta d'água no solo, visto que a lamina de escoamento e muito restrita e não consegue repor a água de solo com vegetação.

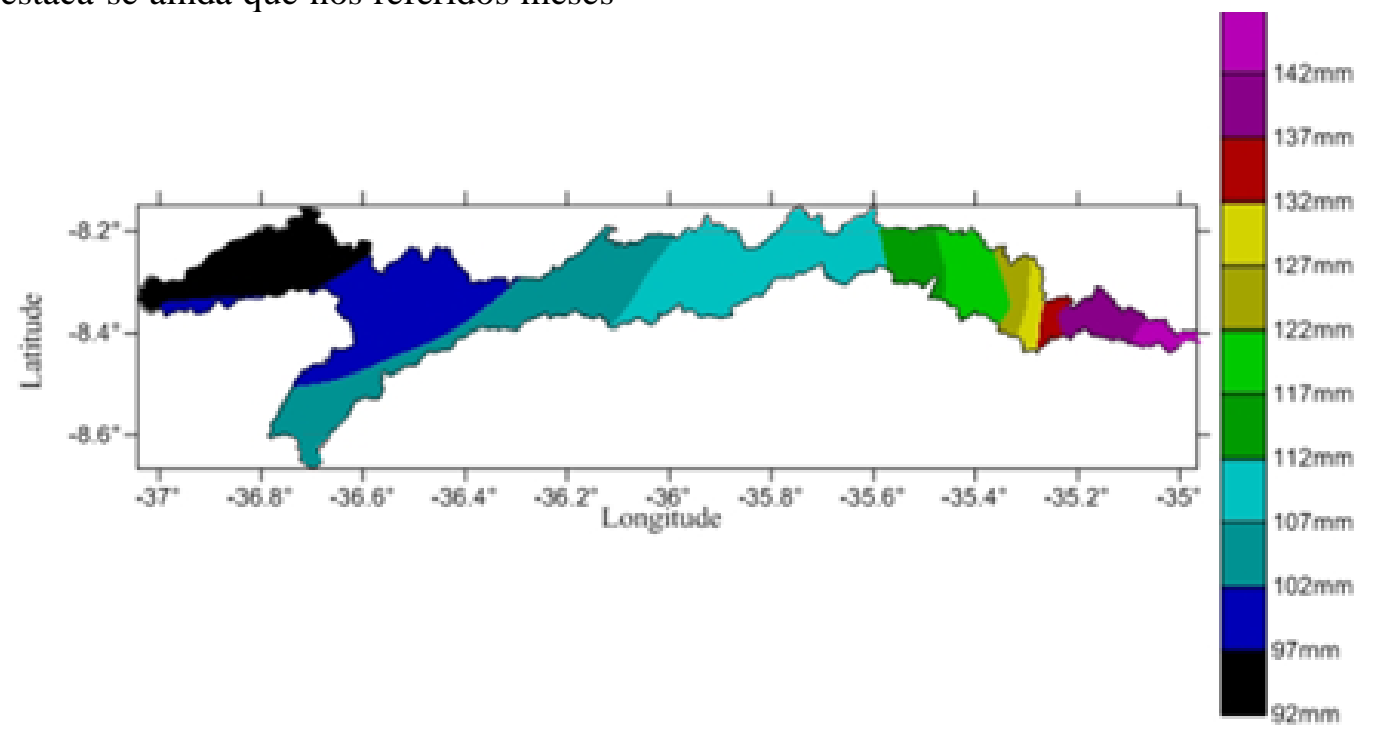

Figura 14 - Meses de maiores índices evapotranspirado (novembro, dezembro, janeiro, fevereiro e março) na área da bacia do rio Ipojuca - PE (Fonte: Medeiros, 2019).

Medeiros et al. (2014) estudando o município de Campina Grande - PB observaram que a ETP obteve uma taxa anual de $1.076,8 \mathrm{~mm}$, com variações de $105,4 \mathrm{~mm}$ no mês de dezembro a $71,3 \mathrm{~mm}$ no mês de agosto. Esta taxa evaporativa está relacionada ao aumento da temperatura e a incidência pluvial em curto intervalo de tempo.

$\mathrm{Na}$ Figura 15 tem-se a variabilidade evaporativa média dos meses (maio, junho, julho, agosto e setembro) de menores índices evapotranspirados para a área da bacia do rio Ipojuca - PE. Destacase as regiões do litoral, zona da Mata e parte este da região com valores de ETP fluindo entre 97 a 77 $\mathrm{mm}$, no restante da região agreste registra-se ETP fluindo entre 72 a $62 \mathrm{~mm}$, estas flutuações estão relacionadas ao termino do período chuvoso. No sertão e alto sertão a ETP flui entre 62 a $72 \mathrm{~mm}$.

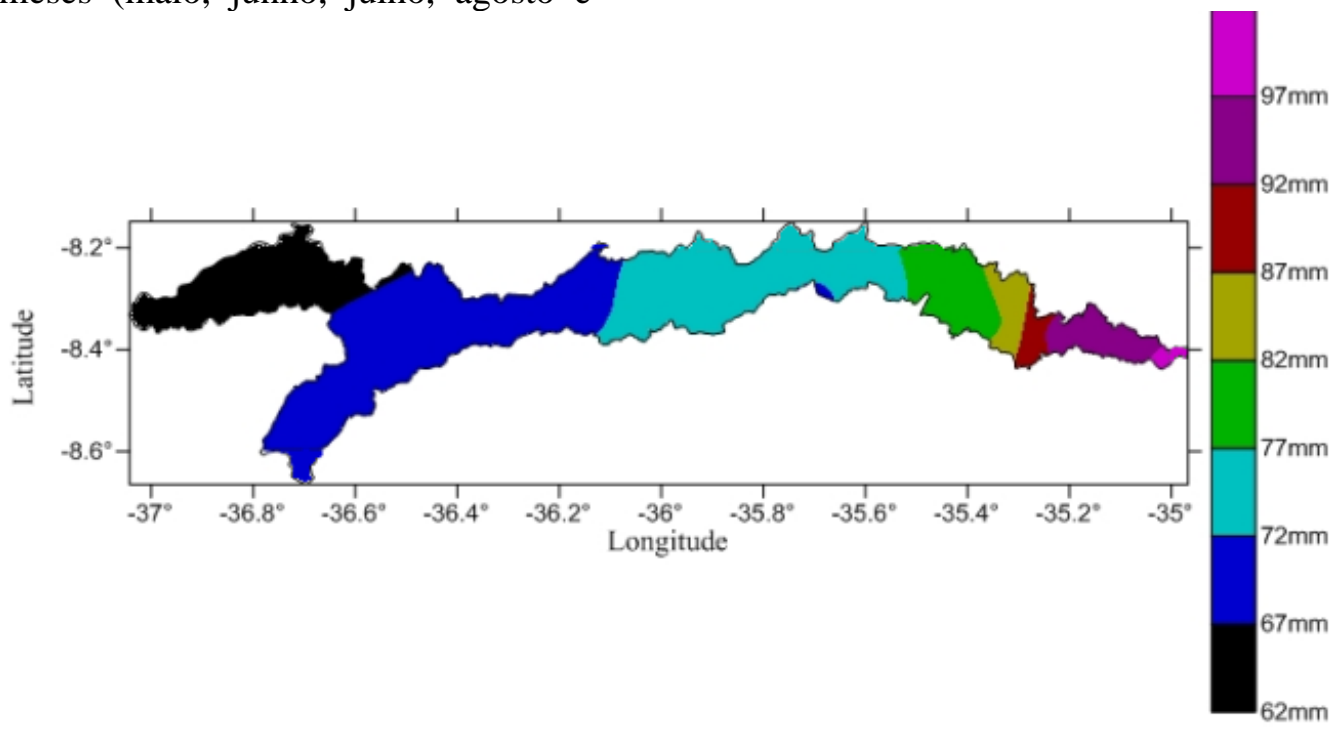

Figura 15 - Meses de menores índices evapotranspirados (maio, junho, julho, agosto e setembro) na área da bacia do rio Ipojuca - PE (Fonte: Medeiros, 2019). 
As variabilidades mensais com flutuações irregulares podem ter ocorrido devido a amplitude térmica dos diferentes municípios, estes resultados estão de acordo com os autores Tubelis et al. (1987) e Medeiros et al. (2018).

\section{CONCLUSÕES}

As estimativas da evapotranspiração mensais para os municípios da área da bacia hidrográfica do rio Ipojuca apresentam dependência da localização geográfica: latitude e longitude e altitude Os dados municipais estimados apresentaram boa acurácia de valores evaporativos e sua consistência é de $95 \%$ de confiabilidade. Os resultados da ETo estão de acordo com vários estudos realizados para a região semiárida do Nordeste Brasileiro.

Esta tendência, é um reflexo da variação espacial da temperatura média do ar mensal na área de estudo.

As cartas e as análises poderão auxiliar no planejamento e gerenciamento de irrigação na região, principalmente por parte dos pequenos irrigantes, que não têm acesso aos dados.

Em todos os meses do ano, as regiões do Litoral e a zona da Mata, demandam as maiores taxas evapotranspiratórias, e as menores taxas ocorrem no Agreste, Sertão e Alto Sertão.

\section{REFERÊNCIAS}

Alvares CA, Stape JL, Sentelhas PC, Gonçalves JLM, Sparovek G. Köppen's climate classification map for Brazil. Meteorologische Zeitschrift, v.22, p.711-728, 2014. https://doi.org/10.1127/0941-2948/2013/0507

Andriotti JLS. Fundamentos de estatística e geoestatística. São Leopoldo: Unisinos, v.3, p.165, 2009.

APAC. Agencia Pernambucana de água e clima. 2020.

Carvalho JRP, Assad ED, Pinto HS. Interpoladores geoestatísticos na análise da distribuição espacial da precipitação anual e de sua relação com altitude. Pesquisa Agropecuária Brasileira, v.47, p.1235-1242, 2012. https://doi.org/10.1590/S0100-204X2012000900008.

Cavalcanti Junior EG, Oliveira AD, Almeida BM. Espíndola Sobrinho, J. Métodos de estimativa da evapotranspiração de referência para as condições do semiárido Nordestino. Semina: Ciências Agrárias, Londrina, v.32, supl.1, p.16991708, 2011

Cavalcanti EP, Silva EDV. Estimativa da temperatura do ar em função das coordenadas locais. IN: Congresso Brasileiro de Meteorologia. 8. 1994. Belo Horizonte, Anais... Belo Horizonte: SBMET, 1994, v.1, p.154-157.

Cavalcanti EP, Silva VPR, Sousa FAS. Programa computacional para a estimativa da temperatura do ar para a região Nordeste do Brasil. Revista Brasileira de Engenharia Agrícola e Ambiental, v.10, n.1, p.140-147, 2006. https://doi.org/10.1590/S1415-43662006000100021
Costa MNM, Medeiros RM, Gomes Filho MF. Variabilidade da evaporação no tanque classe " $A$ " entre o período de 1976 a 2011 e suas comparações com as três décadas e meia e com o ano de 2011, no município de Teresina, Piauí. $7^{\circ}$ Workshop de Mudanças climáticas e Recursos hídricos do Estado de Pernambuco e $4^{\circ}$ Workshop Internacional sobre mudanças climáticas e Biodiversidade. RecifePE, 27 a 29 de outubro de 2015.

Serviço Geológico Do Brasil - CPRM. p.200. 2000

Esteves BS. Avaliação do Kt para estimativa da evapotranspiração de referência (ETo) em Campos dos Goytacazes, RJ. Revista Brasileira de Engenharia Agrícola e Ambiental, v.14, n.3, p.274-278, 2009. https://doi.org/10.1590/S1415-43662010000300006

Fu G, Charles SP, Yu J. A critical overview of pan evaporation trends over the last 50 years. Clim. Change. v.97, p.193-214, 2009. https://doi.org/10.1007/s10584-0099579-1

Gomes AAN, Andrade Júnior AS, Medeiros RM. Evapotranspiração de Referência mensal para o Estado do Piauí. Revista Brasileira de Engenharia Agrícola e Ambiental, v.9, n.4, p.560-564, 2005. https://doi.org/10.1590/S141543662005000400019

Jakob AAE. A krigagem como método de análise de dados demográficos. In: encontro da associação brasileira de estudos populacionais, 13. Ouro preto, Anais... Ouro preto, 2012.

Köppen W. Grundriss der Klimakunde: Outline of climate science. Berlin: Walter de Gruyter, P.388. 1931

Köppen W, Geiger R. "Klimate der Erde. Gotha: Verlag Justus Perthes". Wall-map 150cmx200cm. 1928.

Medeiros RM, Holanda RM, Silva VP. Tendências pluviais e análise da média móvel para São Bento do Una - PE, Brasil. Revista de Geografia (Recife), v.35, n.5, 2018.

Medeiros RM, Holanda RM, Viana MA, Silva VP. Climate classification in köppen model for the state of Pernambuco - Brazil. Revista de Geografia (Recife), v.35, p.219-234, 2018.

Medeiros RM. Estudo Agrometeorologico para o Estado do Pernambuco. 135p. 2016. Distribuição Avulsa

Medeiros RM, Brito JIB, Silva VMA, Melo VS, Costa Neto FA. El Niño/La Niña e sua influência no número de dias com chuva em Bom Jesus - Piauí, Brasil. Revista Verde de Agroecologia e Desenvolvimento Sustentável, v.11, n.2, p.16-23, 2016. https://doi.org/10.18378/rvads.v11i2.3993

Medeiros RM. Planilhas do Balanço Hídrico Normal segundo Thornthwaite e Mather (1955). s.n. 2014.

Medeiros RM, Azevedo PV, Saboya LMF. Classificação climática e zoneamento agroclimático para o município de Amarante - PI. Revista Brasileira de Agricultura Irrigada, v.7, n.2, p.170-180, 2013.

Pires CAF, Strieder AJ. Modelagem Geoestatística de dados geofísicos, aplicada à pesquisa de Au no prospecto volta grande (Complexo Intrusivo Lavras do Sul, RS, BRASIL). Revista Geomática, n.1, v.1, 2006.

Ribeiro MD, Rocha WF, Garcia AJV. Vulnerabilidade Natural À Contaminação dos Aquíferos a Sub-bacia do Rio 
Siriri, Sergipe. Águas Subterrâneas, v.25, n.1, p.91-102, 2011. https://doi.org/10.14295/ras.v25i1.19366

Rocha MM, Yamamoto JK, Watanabe J, Fonseca PP. Studying the influence of a secondary variable in collocated cokriging estimates. Anais da Academia Brasileira de Ciências, v.84, p.335-346, 2012. https://doi.org/10.1590/ S0001-37652012005000017.

Roderick ML, Hobbins MT, Farquhar GD. Pan evaporation trends and the terrestrial water balance. I. Principles and observations. Geogr. Compass, v.3, n.2, p.746-760, 2009. https://doi.org/10.1111/j.1749-8198.2008.00213.x

Roderick ML. et al. On the attribution of changing pan evaporation. Geophys. Res. Lett., v.34, n.17, 2007.

Santos GO, Hernandez FBT, Rossetti JC. Balanço Hídrico como ferramenta ao planejamento agropecuário para a região de Marinópolis, noroeste do Estado de São Paulo. Revista Brasileira de Agricultura Irrigada, v.4, n.3, p.142-149, 2010.

Souza JM, Pereira LR, Rafael AM, Silva LD, Reis EF, Bonomo R. Comparison of methods for estimating reference evapotranspiration in two locations of Espirito Santo. Revista Brasileira de Agricultura Irrigada, v.8, n.2, p.114126, 2014. https://doi.org/10.7127/RBAI.V8N200225

Souza LP, Farias OS, Moreira JGV, Gomes FA, Junior EFF. Comparação de métodos da estimativa da evapotranspiração de referência para o município de Cruzeiro do Sul Acre. Enciclopédia biosfera, v.7, n.12, p.1-8, 2011.

Souza WG, Ribeiro A, Amorim RCF, Souza MJH, Ribeiro CAAS, Facco AG. Geoespacialização da evapotranspiração potencial e real para a bacia do rio Doce - Minas Gerais. In: Anais do Congresso Brasileiro de Meteorologia, 13, Fortaleza, 2004.

Sudene - Superintendência de Desenvolvimento do Nordeste. Dados pluviométricos mensais do Nordeste - Pernambuco. Recife, (Série Pluviometria, 2). 1990.

Thornthwaite CW. An approach toward a rational classification of climate. Geogr. Rev. v.38, p.55-94, 1948.

Thornthwaite CW, Mather JR. The water balance. Publications in Climatology. New Jersey: Drexel Institute of Technology, 104p. 1955.

Tubelis A. Meteorologia descritivas e aplicação agrícola. 540p. 1986. Editora Nobre.

Varejão-Silva MA. Meteorologia e Climatologia. Versão Digital. Recife, 2005. 516p.

Yamamoto JK, Landim PMB. Conceitos e Aplicações. São Paulo: Oficina de textos, 2015. Acesso em: 08 de agosto, 2016. 